\title{
El Ritmo en la Vida
}

\author{
Jorge Olea-Chandía \\ Bailarín y coreógrafo \\ Profesor y coordinador académico \\ Instituto Profesional Escuela Moderna de Música y Danza \\ Santiago, Chile \\ Recibido: 15 de julio de 2019 \\ Aceptado: 20 de diciembre de 2019 \\ Doi: https://doi.org/10.15359/tdna.36-67.3
}

\section{Resumen}

El concepto de ritmo nos conecta, en primera instancia, con la idea de musicalidad, no obstante, los valores o elementos de la ritmicidad no constituyen solo cualidades de la temporalidad y del sonido melódico, sino que también se manifiestan en otros aspectos, como el movimiento, el espacio, la naturaleza o la fisiología. Este ensayo plantea un recorrido por los significados del ritmo hasta llegar a la experiencia rítmica.

Palabras clave: Ritmo, artes, experiencia rítmica, danza, Temas de Nuestra América

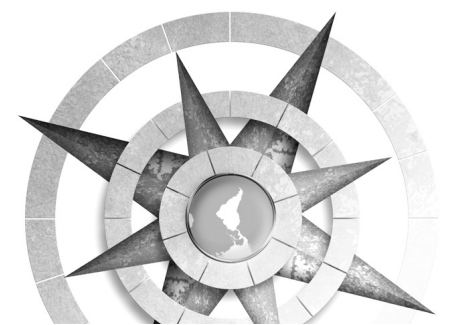

Keywords: Rhythm, arts, rhythmic experience, dance, Temas de Nuestra América

\section{Resumo}

O conceito de ritmo liga-nos, em primeiro lugar, à ideia de musicalidade, no entanto, os valores ou elementos do ritmo não são apenas qualidades de temporalidade e som melódico, mas manifestam-se também noutros aspectos, tais como o movimento, o espaço, a natureza ou a fisiologia. Este ensaio propõe uma viagem através dos significados do ritmo à experiência do ritmo. 
Palavras chave: Ritmo, artes, experiência rítmica, dança, Temas de Nuestra América

\section{La presencia del ritmo en la naturaleza, la biología y el arte}

La etimología de la palabra ritmo proviene del griego rhuthmos o rhythmos, cuya raíz es rheô (Willems, 1964) y del latín rhythmus: acepciones que se pueden traducir como correr, fluir, (Idla, 1982) pero también como forma, orden, posición, según otras acepciones de la cultura jónica (Fraisse, 1976). Una fuerza misteriosamente creadora, componente de todas las actividades humanas, además de poderosamente presente en los fenómenos de la naturaleza, el cosmos y asociada generalmente como referencia a lo kinético. Al respecto, Platón señala en sus escritos: "Ustedes distinguirán el ritmo en el vuelo de un pájaro, en las pulsaciones de las arterias, en el paso del bailarín, en los períodos del discurso" (Fraisse,1976, p. 85). En la actualidad el concepto de ritmo nos conecta, en primera instancia, con la idea de musicalidad, no obstante, los valores o elementos de la ritmicidad no constituyen solo cualidades de la temporalidad y del sonido melódico, sino que también se manifiestan en otros aspectos, como el movimiento, el espacio, la naturaleza o la fisiología.

El ritmo está y ha estado presente en la vida del ser humano desde los inicios de la humanidad. Antiguos testimonios escritos, como el Génesis en la Biblia, mencionan la forma cómo se gestó la creación del universo, su estructura y disposición, por lo tanto, la correcta identificación del término ritmo, motivo de esta ponencia, tiene relación con la forma, el control, la proporción, la medida, la repetición, el contraste, la sucesión, la alternancia, el ordenamiento o la distribución de los elementos de un todo. La esencia del ritmo se abstrae de las cualidades musicales y de las cualidades sonoras, quedando un sustrato que puede percibirse gráfica, plástica, espacial y físicamente, encontrándose este, presente en la vida en las manifestaciones orgánicas e inorgánicas.

El organismo humano ha recibido de la naturaleza el sentimiento y la necesidad del orden y de la proporción, por esta razón, mientras el ser humano existe en el mundo, busca instintivamente el orden y la proporción, esencias y generalidades del ritmo, las cuales son posibles de encontrar y comprobar a cada momento en la forma, en la extensión, en el tiempo y en el espacio, ligadas íntimamente con nuestros sentidos, especialmente los visuales y auditivos. Por esta razón, sin duda, señalaba Aristóteles que "el ritmo es conforme a nuestra naturaleza” (Llonueras, 1942, p. 15).

En efecto, el corazón y los pulmones necesitan un ritmo para funcionar, 
nuestros brazos y nuestras piernas cuando se mueven al caminar necesitan hacerlo rítmicamente, el proceso de nuestra nutrición reclama un ritmo constante. Toda la organización de nuestras actividades orgánicas, así como también nuestras actividades sociales responden a órdenes establecidas.

El fenómeno rítmico para cumplir su función, para ser percibido, apreciado como objeto de estudio, estimulación o creación, necesita la presencia estructuradora y ordenadora de un individuo que lo identifique.

La composición mental o la realidad psicológica de este individuo necesariamente deberá estar conformada por la presencia de un esquema intelectual fundamentado en pares de opuestos o realidades contrarias. Este tipo de mentalidad y su forma de apreciar la realidad corresponde a la mayoría de los seres de la especie humana, siendo originada a través de los tiempos por la relación de este individuo con los fenómenos de la naturaleza, de su corporalidad y de su pensamiento: el paso de las estaciones, los ciclos de la luna, el espíritu versus la materia, la sístole y diástole del corazón, la inspiración y expiración, la elevación y el descenso, la agitación y la calma, el día y la noche, etc.

Esta relación del ser humano con la regularidad e irregularidad temporal es llamada por Luis Advis (1978) en su libro Displacer y trascendencia en el arte con el término psicometrocronía y por la ciencia médica con el nombre de ritmos biológicos: un sistema oscilante en el cual se producen sucesos idénticos a intervalos de tiempo sensiblemente iguales (Fraise, 1976)

La palabra ritmo es entonces la designación que entregamos a la recurrencia de un suceso viviente o no viviente, la relación con sus proporciones espaciales o temporales y un concepto que nos formamos de ellos. Según lo anterior, podemos desprender tres grandes aspectos sobre el tema: el aspecto perceptor, relativo a la percepción y a los procesos intelectuales de carácter asociativo y discriminativo, los elementos temporales, espaciales y enfáticos. El aspecto motor concerniente a los fenómenos orgánico-motores y el aspecto afectivo relacionado con los actos emotivos. No obstante, para que este fenómeno sea considerado ritmo es necesario que cumpla con una característica esencial, la repetición, sin repetición no existe ritmo, aunque la repetición de lo idéntico no es más que una cadencia, un pulso, una constante, el ritmo es percibido al formar parte de una estructura de repeticiones de lo semejante, de lo análogo.

Para una formulación más clara de este principio cabe señalar, a modo de ejemplo, la importancia en el ordenamiento

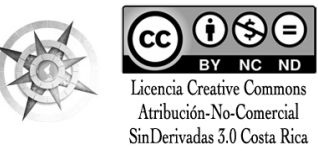


rítmico temporal de la presencia de los factores isocronía ${ }^{1}$ versus heterocronía y de simetría versus asimetría en la estructuración rítmico-espacial. En el espacio y en el tiempo el hombre marca límites, establece puntos de apoyo, ambos intangibles, para interrumpir la continuidad y la uniformidad, satisfaciendo con ello sus necesidades rítmicas.

\section{Elementos constitutivos del ritmo}

\section{Repetición, pulso o constante}

La percepción de un elemento sonoro o espacial que se repite regularmente es la forma rítmica más sencilla. Para ser denominada pulso o constante debe presentarse unida o formando parte de un grupo que se repita idénticamente. Como mencionamos anteriormente, la experiencia rítmica nace de la percepción de la repetición y de la estructura, ambos componentes siempre presentes: la periodicidad de repeticiones de grupos de elementos idénticos o análogos y la estructuración que tiene relación con la composición de estos grupos de duración o forma semejante.

\section{Agrupación}

En ciertas condiciones de sucesión los estímulos se perciben como agrupados y la repetición de estos grupos da lugar a la percepción del ritmo. Si escuchamos en silencio el ruido que produce la caída de gotas de agua de una llave mal cerrada, las oiremos agrupadas de dos en dos o de tres en tres, inclusive cuando la velocidad de caída sea perfectamente regular. Este tipo de agrupamiento subjetivo es una característica de la percepción del ritmo, ya sea visual o sonoro, ya que objetivamente solo ha existido la repetición.

\section{Duración}

Llamado también la cuarta dimensión, el tiempo es el concepto con el cual concretamos lo relativo a la duración, solo a través de la duración es que somos conscientes de su trascendencia para la vida. Los seres humanos adquirimos conciencia de la vida no solamente por los sentidos y por los conceptos que nos formamos de ella, sino también por los diferentes aspectos de nuestra corporalidad, por la materialidad de los movimientos que descomponen la duración y nos hace participar de los acontecimientos temporales. En los siguientes aspectos de la vida humana se refleja la conciencia de la duración:

1 Isocronía: de idéntica duración 
Tiempo físico: Partiendo de la evolución de los astros (ritmos cósmicos), el hombre ha establecido el tiempo físico, astronómico, matemático, cuantitativo. Para medirlo ha creado instrumentos: la clepsidra, el reloj de arena, el reloj, el metrónomo, etc. Este tiempo físico está basado en el movimiento para servir de punto de referencia.

Tiempo fisiológico: Se basa en la participación consciente o inconsciente en el transcurrir del tiempo, a la presencia de sucesos idénticos en intervalos de tiempo sensiblemente iguales, a estos intervalos se les ha denominado ciclos o períodos de vida y han dado origen a los ritmos biológicos, ${ }^{2}$

2 Ritmos espontáneos: Su periodicidad es autónoma y actúan de modo espontáneo, dependiendo del metabolismo celular, del corazón, temperatura corporal. Ritmos desencadenados: Una excitación no periódica los desencadena, la ausencia o presencia de luz en algunas plantas da origen a movimientos oscilatorios en sus hojas. Ritmos inducidos: Siendo de carácter periódico espontáneo, las ondas alfa del cerebro, al ser estimuladas con determinados ritmos lumínicos externos, tienden a cambiar su estructura periódica, si el estímulo cesa, el ritmo torna a su estructura básica. Ritmos rápidos: Se incluyen en esta categoría los acaecidos entre algunas fracciones de segundos y alrededor de veinte horas, los movimientos de las pestañas, las ondas cerebrales, los movimientos según Paul Fraisse en Psicología del ritmo.

Tiempo afectivo: Los diversos estados afectivos, emociones y sentimientos, influyen en la conciencia del transcurso del tiempo. Este puede variar según los individuos y las circunstancias, la impaciencia tiende a alargarlo y la alegría generalmente a hacerlo fugaz. Este tiempo se caracteriza por ser subjetivo y ligado estrechamente con lo inestable. Se le conoce también con el término de tiempo psicológico. La emoción que el ritmo provoca proviene de la repetida sucesión de las fases de deseo o espera y satisfacción.

Tiempo mental: Se basa en la capacidad humana de establecer, de crear, un tiempo mentalmente, de elaborar la proporcionalidad de una obra. Difiere del tiempo físico en el hecho de poder ser concebido en un solo instante. Se

de la respiración y del corazón. Ritmos adquiridos: También llamados ritmos condicionados al tiempo, basados en los resultados de los experimentos con animales de Pavlov. Ritmos circadianos o nictemerales: correspondientes a los desarrollados en el período de veinticuatro horas que supone el día y la noche. Ritmos lentos o de baja frecuencia: Se denomina así a los que su período se desarrolla en una duración mayor de veinticuatro horas, por ejemplo: el ciclo ovárico en la mujer, el ritmo de las estaciones, las evoluciones de la luna en torno a la Tierra. 
pueden concebir las proporciones de una obra, cualquiera que sea su dimensión, modificar con el pensamiento las proporciones respectivas e imaginar su realización en el tiempo.

\section{Arsio y tesio}

El sentido de propuesta y de respuesta constituyen los ejes fundamentales sobre los que se basa el hecho rítmico, se referían primitivamente al núcleo elemental del movimiento coreográfico, levantar el pie y luego dar el paso, esta primera relación posibilitó la aplicación de este principio no solo teóricamente, sino de forma práctica en determinadas artes como las literarias y las visuales, donde se pudiera pensar que el factor temporal no es un elemento primordial, ya que sus componentes iniciales y finales coexisten, están presentes en todo momento, pero desde el punto de vista del receptor de la obra, este necesariamente resuelve sus intereses y dudas a través del tiempo.

Todo aquello que prepara un futuro o está en tensión hacia un acontecimiento que se espera crea un ritmo (expectativa y resolución); en esta espera de acontecimientos, de soluciones, radican las típicas reacciones emocionales que caracterizan la vivencia rítmica y tensional, vivencia que no se transforma en una contemplación pasiva, sino en un proceso activo que busca y exige una complementación de las proposiciones expectantes y suspensivas (Advis, 1979).

\section{Pausa}

El intervalo de tiempo o la dimensión espacial que en una estructura rítmica separa a un elemento o grupo de elementos de otro u otros, permitiendo la percepción de agrupaciones de tipo sonoro, motriz, emotivo, visual.

La pausa tiene como función hacer resaltar o distinguir aspectos determinados, permitir el descanso y también enlazar grupos de elementos. No puede describirse como un tiempo muerto, un espacio vacío o un fondo respecto a una figura, sino que la pausa, intervalo o silencio es en sí misma un valor rítmico. Una acción finaliza y se detiene por una fracción de segundo creando un precedente, que es el impulso de la acción sucesiva.

Cuando se habla de ritmo, se habla también de silencio o pausa, pues estos son el tejido fundamental sobre el que se desarrolla el ritmo. Aquello que diferencia dos ritmos no son los sonidos o movimientos producidos, sino el modo cómo se organiza el silencio o la pausa.

\section{Intensidad o acentuación}

Cuando nos encontramos frente a una situación perceptible cualquiera nuestro 
intelecto tiende instintivamente a atribuir mayor atención a determinados puntos equidistantes, con el fin de formar pequeñas divisiones que faciliten la comprensión del fenómeno. Estas divisiones no son azarosas, sino que están determinadas por cierto grado de diferenciación de algunos elementos sobre los demás.

Estos elementos se encuentran acentuados o intensificados a través del uso de mayor o menor energía, en el caso de la música, la voz hablada o el movimiento y a través de densidad, textura, tono, en las artes visuales.

La acentuación es un llamado de atención y constituye un factor de relevancia en la estructura y percepción rítmica, ya que sin su presencia todos los elementos de una composición adquieren igualdad de valor, por lo tanto, una repetición sin diferenciación alguna. La acentuación de las formas espaciales posibilita la atención o el impacto tensional a través de formas contrastantes y también el reposo por medio de combinaciones de color que provoquen alivio.

En la relación del movimiento y el ritmo podemos señalar que la importancia de la acentuación radica en que las variaciones de intensidad de lo leve a lo fuerte proporcionan las pulsaciones, el flujo y reflujo del impulso muscular del que nacen y crecen las frases y los ritmos de la danza (Love, 1970)

\section{Espacio}

Al referirnos a la relación del espacio con el sentido y la experiencia rítmica, no podemos dejar de señalar que sus principales propiedades son las dimensiones espaciales y la forma. Forma y dimensión nos remiten a un juego de proporciones y se tiende a hablar de ritmo espacial cuando la relación de las proporciones es particularmente armónica. La cultura occidental se ha visto fuertemente influenciada por la tradición griega, y en particular por la influencia pitagórica, que ha buscado los cánones de belleza, ritmo y armonía en la correspondencia con números y estructuras.

De estas teorías de correspondencia, la que tiene relación con la proporción divina, el número de oro o la sección áurea es la que más tiempo ha perdurado, habiendo sido por épocas transmitida de forma casi esotérica: para que un todo dividido en partes desiguales parezca hermoso, desde el punto de vista de la forma, debe haber entre la parte menor y la mayor la misma relación que entre la mayor y el todo (Ghyka, 1983). Se llama a esta teoría la ley de las proporciones y según ella se cumple en las proporciones del cuerpo humano, de las especies animales, en la forma del huevo, 
en las artes visuales, en ciertos templos griegos, en botánica y en música.

El ser humano ha adquirido el sentido innato de la estructura a través de miles de experiencias con configuraciones ópticas. Todos los días los sentidos visuales reciben la impresión de la forma de los objetos, desde el volumen de un vaso para beber agua y las imágenes presentadas en el cine hasta los inmensos diseños arquitectónicos y las montañas. Es innumerable la sucesión de diseños que la visión confronta durante la vida. Estos diseños se pueden diferenciar por la regularidad de sus proporciones en simétricos y asimétricos. Cuando aludimos al término simetría nos estamos refiriendo a posición, forma y medida de los elementos de un conjunto en relación con un eje.

La simetría sugiere igualdad de medidas, estabilidad, equilibrio, y podríamos pensar que también monotonía, pero cuando se trata del concepto de simetría en el arte este debe ser vital, no estático ni repetitivo, estar constituido por elementos que difieran, por lo diverso, por lo dinámico, es decir, por una buena utilización del ritmo en la forma y la ubicación.

\section{La experiencia rítmica}

El contacto, la experiencia con el ritmo, posibilita el afinamiento de las cualidades de la percepción y un desarrollo de las capacidades psicomotrices, ya que permite establecer una comunicación y coordinación con el mundo externo, afianzar el sentido de la armonía plástica y educar el movimiento corporal.

El pesado esfuerzo de un trabajo cualquiera, al ser apoyado y vivificado por el ritmo, regulariza los movimientos impuestos por el mismo trabajo, disminuye el cansancio, ya que todo elemento dinámico (acento, pausa, duración, etc.) es excitante, estimula con su impulso las energías corporales y produce placer. El ritmo relaja, alivia, automatiza el movimiento. El proceso rítmico permite que el trabajo sea menos pesado. Una tarea que obligadamente deba realizarse de acuerdo con el tiempo propio es más difícil que cuando se efectúa ajustándose a un tiempo determinado desde fuera. En un proceso de trabajo rítmico, desaparece la concentración de la voluntad, ya que se comienza a actuar automáticamente y la acción de la voluntad disminuye, lo que quiere decir que el cuerpo humano es todo lo contrario a una máquina, latente y coordinado, aún aquellos órganos cuyo accionar puede parecer mecánico, ya que no es consciente su función, no dejan de tener su sensibilidad respecto a la dinámica de su funcionamiento. 
De esta manera se concluye que el contacto de la persona con la experiencia rítmica permite el desarrollo del sentido de la orientación en el espacio y por ende su lateralidad, equilibrio y mejor coordinación corporal, también en otro aspecto la socialización, al permitirle aunarse con otros en una actividad común, favorece la destreza y la coordinación con objetos, ayuda a tomar posesión del mundo exterior a través de la imitación, la identificación y facilita la articulación y expresión del lenguaje motor y verbal a través del movimiento y de la palabra.

\section{Bibliografía}

Advis, L. (1978). Displacer y trascendencia en el arte. Santiago de Chile: Editorial Universitaria.

Fraisse, P. (1976). Psicología del ritmo. Madrid: Ediciones Morata.

Ghyka Matila. (1983). Estética de las proporciones en la naturaleza y las artes. Barcelona: Editorial Poseidón.

Idla Ernst. (1982). Movimiento y ritmo. Barcelona: Ediciones Paidós.

Love, Paul. (1970). Terminología de la danza moderna. Buenos Aires: EUDEBA Editorial de Buenos Aires.

Llongueras, J. (1942). El ritmo. Barcelona: Editorial Labor.

Willems, E. (1964). El ritmo musical. Buenos Aires: EUDEBA 